\title{
Laboratory Exercise Demonstrating the Importance of Leaves in the Rooting of Herbaceous Stem Cuttings
}

\author{
Michael Marcotrigiano ${ }^{1}$ and Susan P. McGlew ${ }^{2}$ \\ Department of Plant and Soil Sciences, University of Massachusetts, \\ Amherst, MA 01003
}

Additional index words. coleus, auxin, indole-3-butyric acid, sucrose, education, teaching

\begin{abstract}
A teaching exercise that rapidly and inexpensively demonstrates the effects of leaf reduction on the rooting of stem cuttings is described. Coleus stem cuttings with whole leaves, half leaves, or no leaves are placed in sand on either misted or nonmisted greenhouse benches. Rooting response is recorded by ranking root systems by comparison to a diagram. A demonstration is also described that uses leafless cuttings cultured in vitro on solidified media containing a carbohydrate and/or auxin source. This demonstration gives students information that will help them speculate on the physiological reasons for the poor rooting response of leafless herbaceous cuttings.
\end{abstract}

Many plant species are propagated by stem cuttings. Cuttings from species possessing large leaves can transpire excessively, causing a reduction in rooting or failure to root. In addition, leafy cuttings occupy more bench space than leafless cuttings, affecting the efficient use of propagation facilities. Therefore, leaf surface area is frequently reduced before placing cuttings under mist.

Since leaves provide carbohydrates, auxin, and rooting cofactors, their removal can have profound effects on rooting (Breen, 1974; Reuveni and Raviv, 1981). The following laboratory exercise demonstrates the effects of leaf reduction on the rooting of stem cuttings. Coleus $\times$ hybridus (Benth.) was chosen because rapid and reliable results are obtained early in the semester, permitting enough time for students to write a report on their findings. This exercise has been incorporated into a 14 -week plant propagation course that is attended by students in a 2year program at the Stockbridge School of Agriculture, Univ. of Massachusetts, Amherst, and by undergraduates (mostly sophomores) majoring in plant and soil sciences. Experiment 1 is performed by the students and Expt. 2 is prepared in advance by the instructor as a demonstration to illustrate the relative importance of carbohydrates and auxin in rooting. The exercise was devised because students desired an explanation for the poor rooting response of leafless cuttings.

Received for publication 8 May 1989. Paper no. 2997 of the Massachusetts Agricultural Experiment Station. We thank Lesley A. Spokas for assistance in statistical analysis and Edward Nowak, teaching assistant for the course. The cost of publishing this paper was defrayed in part by the payment of page charges. Under postal regulations, this paper therefore must be hereby marked $a d$ vertisement solely to indicate this fact.

'Associate Professor.

${ }^{2}$ Research Technician.
Experiment 1. Effects of leaf reduction on the rooting of stem cuttings

Objective: To determine the effect of the reduction of leaf surface area on the rooting of misted and nonmisted stem cuttings.

Materials:

a) 18 uniform terminal cuttings from 'Golden Bedder' coleus

b) Single-edge razor blade

c) Propagation house containing both misted and mist-free bench space

Procedure:

1) Divide cuttings into three groups of six.

2) Set aside Group 1. This group should consist of cuttings with intact leaves.

3) Reduce the leaf area of Group 2 by cutting off the distal half of each leaf perpendicular to the midvein.

4) Remove all leaves from cuttings in Group 3 by cutting through the lower portion of the petiole.

5) Place three cuttings from each group on a bench with mist and place the remaining three from each group on a bench without mist.

6) Dibble holes into flats of sterile sand, spacing holes $\approx 2.5 \mathrm{~cm}$ apart with $7.5 \mathrm{~cm}$ between rows. Place one cutting per hole. There should be six treatments: full leaf/mist, half leaf/mist, no leaf/mist, full leaf/no mist, half leaf/no mist, and no leaf/ no mist.

7) Water cuttings thoroughly with tap water using a watering can. Keep sand in nonmisted flats moist by frequent watering.

8) After cuttings have rooted, carefully dig up all cuttings and, using Fig. 1 as a guide, rank the rooting response of each cutting from 1 (worst) to 5 (best). Calculate the average rank for each treatment.

Experiment 2. Combined and separate effects of sucrose and auxin on the rooting of leafless coleus cuttings

Objective: To determine whether sucrose or auxin are limiting factors when leaves are removed from herbaceous cuttings.

Materials:

a) Leafless terminal coleus cuttings $\approx 5$ $\mathrm{cm}$ long

b) $10 \%$ Clorox solution $(0.525 \%$ sodium hypochlorite)

c) Foil-covered beakers containing sterile distilled water

d) $25 \times 95-\mathrm{mm}$ vials containing $10 \mathrm{ml}$ of water-based, agar-solidified medium as described under Procedure

e) Tissue culture lab facility, including laminar flow hood

Procedure:

1) Make a factorial media array consisting of two levels of sucrose $(0$ and $20 \mathrm{~g} \cdot$ liter $\left.^{-1}\right)$ and two levels of auxin ( 0 and $5.0 \mu \mathrm{m}$ indole-3butyric acid) in all combinations in aqueous solution. No minerals, vitamins, etc. are added to the media. Media are solidified with Difco Bacto agar $\left(7 \mathrm{~g} \cdot\right.$ liter $\left.^{-1}\right)$. One millimolar of auxin stock is made by dissolving $203 \mathrm{mg}$ of indole3-butyric acid (IBA) in $5 \mathrm{ml}$ of 1 $\mathrm{N} \mathrm{KOH}$ and bringing the volume to 1 liter with water.

2) In a laminar flow hood, surface-sterilize coleus cuttings for $15 \mathrm{~min}$ in bleach solution followed by three rinses in sterile water.

3) Trim off bleached basal stem tissue aseptically.

4) Place cuttings vertically, one per vial, in the medium so that the most
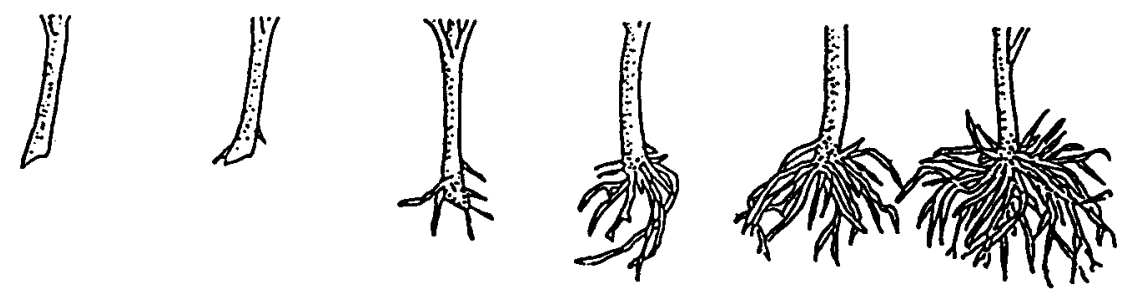

0 $\quad 1 \quad 2 \quad 3$
4

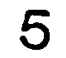




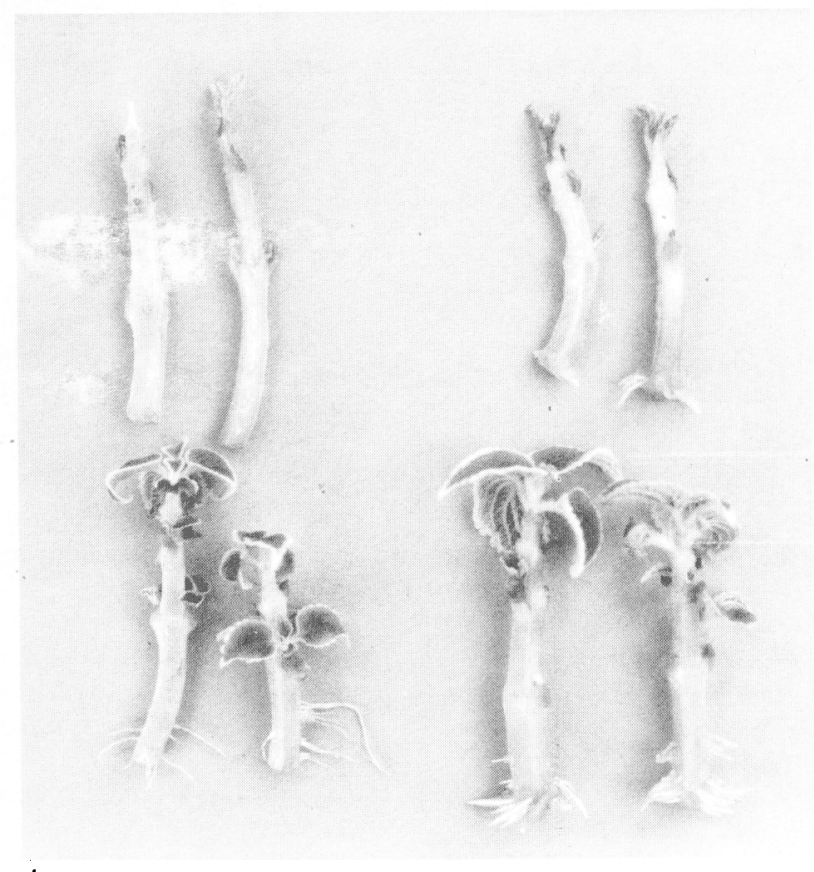

Fig. 2. Effect of sucrose and auxin alone and in combination on in vitro rooting of leafless stem cuttings of coleus inserted in agar-solidified media. (top left) No sucrose, no auxin; (top right) sucrose, no auxin; (bottom left) no sucrose, auxin; (bottom right) sucrose and auxin.

basal node is slightly above the agar surface, with between 0.5 and $1 \mathrm{~cm}$ of internodal stem inserted in the agar.

5) Place cuttings under $16 \mathrm{hr}$ on/ $8 \mathrm{hr}$ off of cool-white fluorescent light (45 $\mu \mathrm{mol} \cdot \mathrm{s}^{-1} \cdot \mathrm{m}^{-2}$ ) in either an incubator (25C constant) or on a growth cart (ambient Laboratory temperatures).
6) Evaluate rooting response in 10 to 14 days.

For Expt. 1, data were generated by students and statistical analysis was provided by the instructor. There were no significant differences between years (1986 and 1987), thereby indicating the repeatability of this exercise. Data were analyzed as a split plot, with mist regime as whole plots and leaf reduction as subplots. The four laboratory sec- tions were treated as replications. While statistically significant interactions between leaf and misting treatments existed within the treatment levels tested, plotting of main effects indicated differences in magnitude but not in direction. Therefore means of main effects were compared. Rooting ranks for mist (3.3) were significantly greater than those for no mist $(2.5)(\mathrm{LSD}) \pm 0.2, \alpha=0.05)$. Rooting rank means for leaf reduction effects were $4.2,3.2$, and 0.9 for no, $50 \%$, and $100 \%$ removal, respectively; all differences were significant at $P \leq 0.05$. There was no significant effect for lab section (i.e., replication).

Typical results of in vitro responses are presented in Fig. 2. This experiment clearly demonstrates that both auxin and sucrose interact, the presence of both giving the best root initiation and root development. Early root development leads to axillary bud growth. In addition, auxin alone orsucrose alone results in a better root system than the control.

Using results from both experiments, students write a laboratory report that includes objectives, materials, procedures, observations, and discussion. Students are encouraged to suggest additional experiments that would assist in the interpretation of results and are asked to include in their discussions the interaction of transpiration, auxins, and carbohydrate levels as they relate to the six treatments in Expt. 1.

\section{Literature Cited}

Breen, P.J. 1974. Effect of leaves and carbohydrate content and movement of ${ }^{14} \mathrm{C}$-assimilate in plum cuttings. J. Amer. Soc. Hort. Sci. 99:326-332.

Reuveni, O. and M. Raviv. 1981. Importance of leaf retention to rooting avocado cuttings. J. Amer. Soc. Hort. Sci. 106:127-130. 